\section{Use of Amplified Fragment Length Polymorphism Markers for Celery Cultivar Identification}

\author{
Genyi Li and Carlos F. Quiros ${ }^{1}$ \\ Department of Vegetable Crops, University of California, Davis, CA 95616
}

Additional index words. amplified fragment length polymorphism, Apium graveolens var. dulce, DNA fingerprinting, DNA typing, breeding, genetics, breeding

Abstract. DNA samples from 21 cultivars of celery (Apium graveolens L. var. dulce) were subjected to amplified fragment length polymorphism (AFLP) analysis. The most informative adapter combination was EcoRI-TaqI. All cultivars could be distinguished from each other by their unique fingerprints based on 73 markers. The program NTSYS grouped the cultivars in three main clusters according to their origin. The groupings observed agreed, with a few exceptions, with those expected by historical accounts and previous analyses based on biochemical and ramdomly amplified polymorphic DNA (RAPD) markers.

According to Vilmorin (1950), celery was introduced from France to North America in 1887 in the form of two cultivars, the selfblanching 'Paris Golden Yellow Self-Blanching' and a green cultivar called 'Pascal'. In the U.S. seed trade business they were known as 'White Plume' and 'Giant Pascal', respectively. 'White Plume' and 'Giant Pascal' are the chief progenitors of U.S. modern cultivars, with little introgression from other accessions. Furthermore, these two cultivars were related since presumably they derived by selection from the olderFrench cultivar Solid Golden White Celery (Vilmorin, 1950). Based on historical accounts and utilization of biochemical and molecular markers, we have attempted to trace the pedigrees of existing celery cultivars. These markers included isozymes, crown storage proteins (Quiros et al., 1987), and random amplified polymorphic DNA (RAPD) markers (Yang and Quiros, 1993). The number of informative markers has been limited because of the narrow genetic base of U.S. celery cultivars, impeding detection of polymorphism. Furthermore, the large size of the celery genome, estimated to be $3 \times 10^{9} \mathrm{bp}$ (E. Earle, personal communication), is also a hindrance for single/low copy marker development because of the large proportion of repetitive DNA. The advent of high-marker throughput techniques, such as amplified fragment length polymorphism (AFLP)(Vos et al., 1995), makes it feasible to produce a larger

Received for publication 6 July 1999. Accepted for publication 9 Oct. 1999. Research supported by the California Celery Research Advisory Board. We thank Vincent D'Antonio and Anita Kuras for technical assistance; and Roger Chetelat and Darush Struss for reviewing the manuscript. The cost of publishing this paper was defrayed in part by the payment of page charges. Under postal regulations, this paper therefore must be hereby marked advertisement solely to indicate this fact.

${ }^{1}$ To whom reprint requests should be addressed. E-mail address: cfquiros@ucdavis.edu number of informative markers that are polymorphic for the different cultivars tested. We successfully applied this technique for celery cultivar fingerprinting after some pertinent modifications to increase the number of polymorphisms.

\section{Materials and Methods}

The cultivars included in this study (Table 1) are open-pollinated but highly uniform, except for the line UC1, which is a breeding line. The DNA was extracted from young, actively growing leaves collected from pools of 5 to 10 plants following the protocol of Yang and Quiros (1993).

AFLP procedures were performed according to the protocol of Vos et al. (1995). Two sets of adapters were used: EcoRI-MseI and EcoRITaqI. The sequences of all adapters and primers were the same as those given in the protocol, and their oligonucleotides were commercially (FR) cultivars indicated in the second column. synthesized. Each adapter was produced by using similar molar concentrations of the two complementary oligonucleotides, denaturing the DNA for 5 min at $94^{\circ} \mathrm{C}$, followed by annealing at $24^{\circ} \mathrm{C}$ (temperature reduced over a 2 -h period, at $2{ }^{\circ} \mathrm{C} / \mathrm{min}$ ). All restriction enzymes, T4 DNA ligase, and T4 polynucleotide kinase were obtained from New England Biolabs (Beverly, Mass.). The restriction digestion was performed by adding EcoRI and MseI simultaneously to the genomic DNA in buffer 2 and stirring for 3 $\mathrm{h}$ at $37^{\circ} \mathrm{C}$. When the EcoRI-adapter and TaqIadapter were used, a two-step digestion was performed. First, the genomic DNA was digested by EcoRI in TaqI buffer for $3 \mathrm{~h}$ at $37^{\circ} \mathrm{C}$, then $\mathrm{Taq}$ I enzyme was added and incubated for $3 \mathrm{~h}$ at $65^{\circ} \mathrm{C}$. The primers for the first amplification were nonselective, whereas those for the second amplification had three selective nucleotides as follows: EcoRI plus GAC, GAG, GCA, GCC, TCA, TCC, TGA, TAG, ATT, ATC, AAT, ACA, AGA, TAA, AAC; MseI plus CAC, CAA, and TaqI plus AGC, CAT. The ligation, primer-labeling, two-step PCR and gel analysis were the same as in the protocol. Only the EcoRI-primers were end-labeled using $\left[{ }^{\gamma-33} \mathrm{P}\right]$ ATP. The amplification was repeated at least three times to assure reproducibility of the bands used for describing each cultivar.

Presence of specific bands polymorphic among the cultivars was scored as " 1 ," whereas absence of these bands was scored as " 0 ." Bands common to all cultivars were considered noninformative. The similarity coefficient matrix, clustering, and phylogenetic tree construction were performed with the NTSYS package, version 2.01 (Rohlf, 1993), based on the unweighted pair group method with arithmetic average (UPGMA).

\section{Results and Discussion}

Previous reports on celery cultivar fingerprinting and classification by origin were based on $\approx 12$ combined crown storage protein and isozyme markers (Quiros et al., 1987). Later,

Table 1. Celery cultivars used in this study and their sources. Self-blanching (SB) and Fusarium-resistant

\begin{tabular}{lccc}
\hline Cultivar no. & Cultivar & UCD accession no. and unique traits & Source \\
\hline 1 & Golden Self Blanching & A33 (SB) & Burpee Seed \\
2 & Transgreen & A35 & Ferry Morse \\
3 & Tendercrisp & A36 & Ferry Morse \\
4 & Surepack & A37 & Ferry Morse \\
5 & Florida 2-14 & A38 & Keystone \\
6 & Florida 683K & A39 & Keystone \\
7 & Tall Utah 52-70R & A40 & Keystone \\
8 & Florimart & A43 & Keystone \\
9 & Summit & A74 & Ferry Morse \\
10 & Deacon & A76 & Moran Seeds \\
11 & Bishop & A77 & Moran Seeds \\
12 & Tall Golden Self Blanching & A93 (SB) & Royal Sluis \\
13 & UC1 & A203 (FR) & UC Davis \\
14 & Tall Utah 52-75 & A233 & Sunseeds \\
15 & Calmario & A255 & Harris Moran \\
16 & Ventura & A256 & Ferry Morse \\
17 & Picador & A285 (FR) & Pybas Seed \\
18 & Matador & A286 (FR) & Pybas Seeds \\
19 & Conquistador & A287 & Pybas Seeds \\
20 & Starlet & A288 (FR) & Royal Sluis \\
21 & Promise & A300 (FR) & UC Davis \\
\hline
\end{tabular}




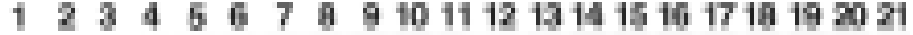

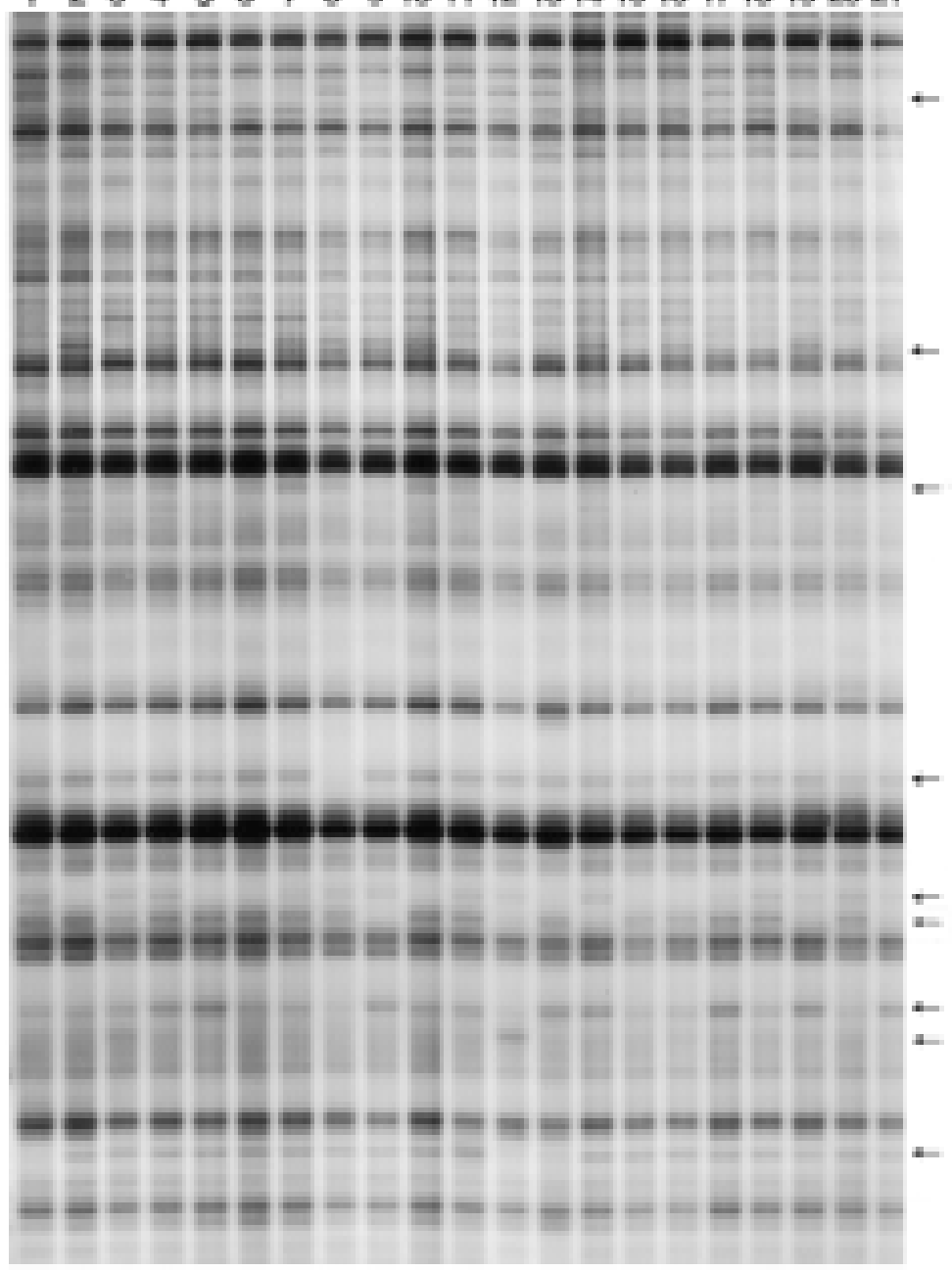

Fig. 1. Sample of AFLP fingerprint for 21 celery cultivars disclosed with primer combination EcoRI+ATT and TaqI+AGC. Arrows show eight polymorphic bands. Numbers on top correspond to cultivar numbers in Table 1. as marker technologies progressed, the number of markers for this type of analysis could be tripled by applying RAPD markers (Yang and Quiros, 1993). With the advent of AFLP markers, we assessed them for celery cultivar identification. However, our original attempts using the conventional restriction enzymes EcoRI and MseI, normally recommended for generating AFLP restriction fragments for amplification, failed to disclose enough polymorphism in celery. Among 10 primer combinations tested, over 1000 bands were amplified, but only 15 showed polymorphism. This poor level of polymorphism probably was due to the large size of the celery genome, which seems to consist of large amounts of repetitive DNA (Yang and Quiros, 1997). Additionally, we tried other enzyme combinations, such as HindIII/MseI, PstI/ MseI (data not shown), and EcoRI/TaqI, finding that the last one was the most useful. Among the 22 primer combinations of EcoRI/ TaqI used, more than 100 bands were produced per primer combination with an average of 10 polymorphic bands. No major bias in the number of polymorphic bands per combination was detected. Based on the EcoRI/TaqI enzyme combination, we were able to select 73 markers for the identification of old and new celery cultivars, including the newly released Fusarium-resistant cultivars (Fig. 1). Analysis of the AFLP profiles by the program NTSYS disclosed three main clusters (Fig. 2). The first one included the two yellow (self-blanching) cultivars and the green cultivar Tendercrisp. The second cluster was the largest one, consisting of two subgroups of six and nine cultivars each. All of these 15 cultivars, however, may be considered as a single large group, since most of them are probably related by origin according to historical accounts (Guzman et al.,

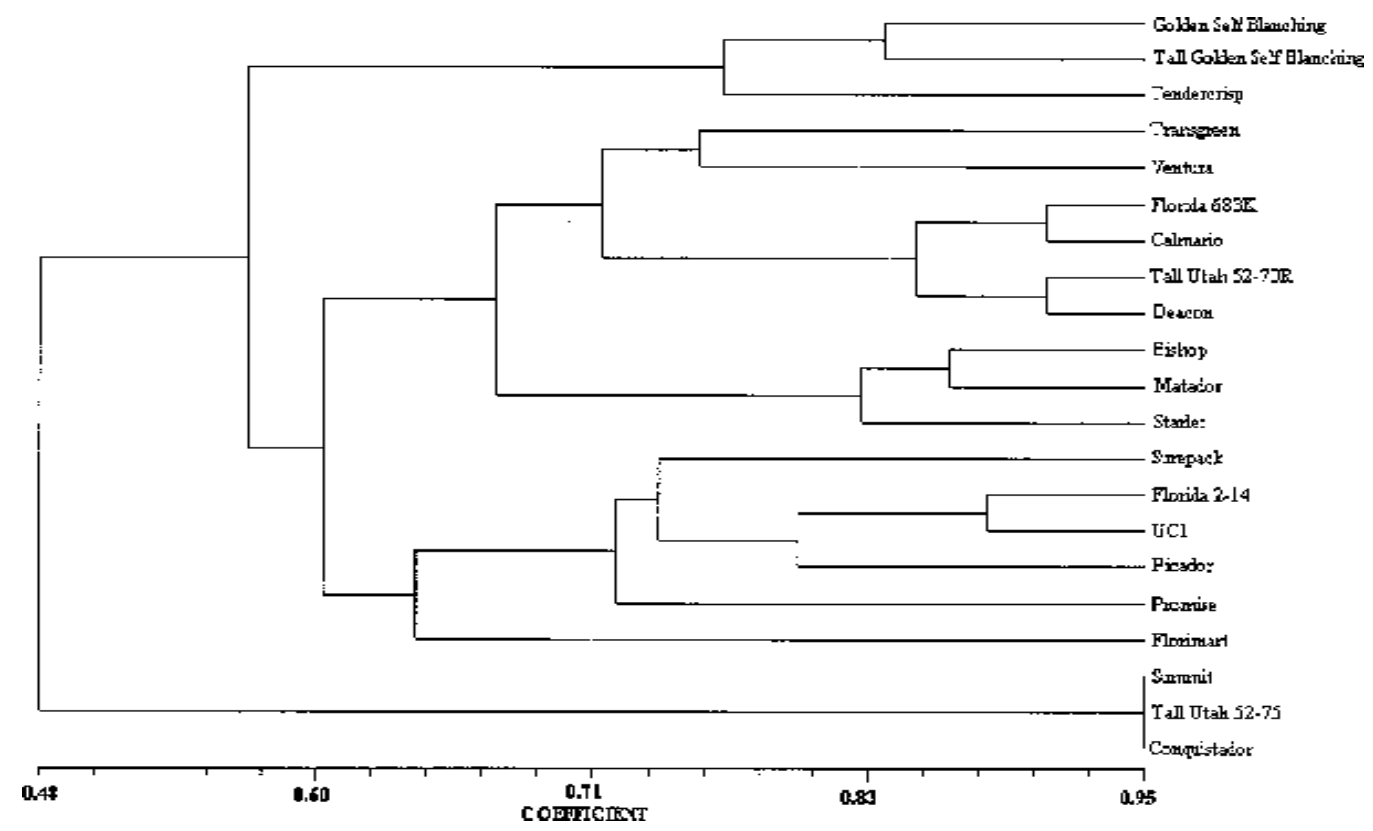

Fig. 2. Relationship among celery cultivars based on AFLP markers based on UPGMA using the NTSYS-pc program. Similarity coefficients are shown at the bottom of the figure. 
Breeding, Cultivars, Rootstocks, \& Germplasm Resources

Table 2 . Similarity coefficients among 21 celery cultivars. ${ }^{2}$

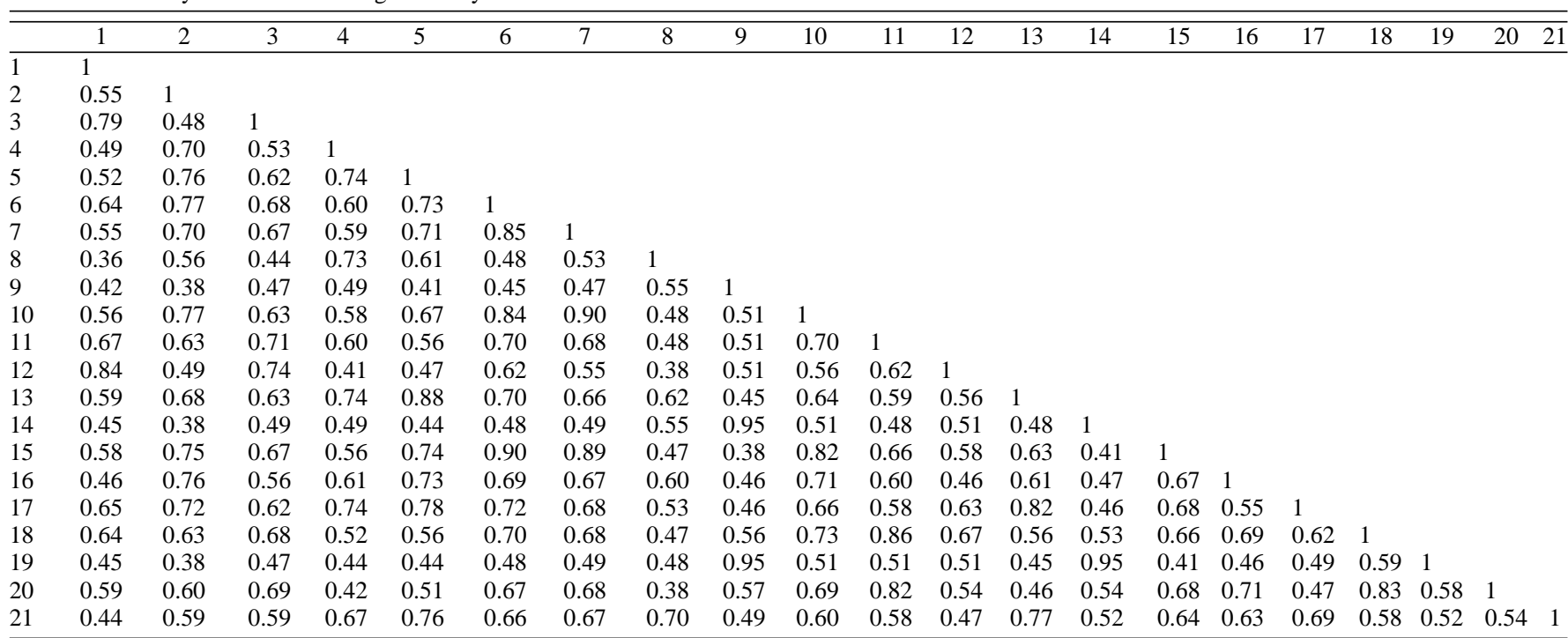

${ }^{2}$ See Table 1 for names of cultivars.

1973) and to previous marker studies (Quiros et al., 1987; Yang and Quiros, 1993). This group included 'Tall Utah 52-70R' and Fusarium-resistant cultivars such as 'Matador', 'Starlet', 'Promise' and 'Picador'. These were derived from UC1, a breeding line obtained by crossing and backcrossing Fusarium-resistant celeriac to 'T.U. 52-70R' (Orton el al., 1984). UC1 was the predominant source for developing resistant cultivars to this disease by the seed industry. The third cluster consisted of three very similar cultivars, 'Summit', 'T.U. 52-75', and 'Conquistador'. They differed from each other by only four or five of 73 polymorphisms (similarity coefficient 0.96 and 0.95 , respectively, Table 2). In general the AFLP classification for most of the cultivars is consistent with previous classifications based on biochemical (Quiros et al.,1987) and RAPD markers (Yang et al., 1993). The main discrepancy was the clustering of 'Tendercrisp' with the yellow celery cultivars. Nevertheless, 'Tendercrisp' differs by 15 to 17 markers (similarity coefficient 0.79 and 0.74 , respectively; Table 2). Since 'Tendercrisp' is an old cultivar (Guzman et al., 1973), it may have had a self-blanching celery in its pedigree. Another surprise was the separation of 'Florida 683' from 'Florida 2-14', which differed by 18 markers ( similarity coefficient 0.73 ; Table 2 ). These cultivars are supposed to be sister lines selected from single plants of 'T.U. 52-70'. However, this result is consistent with the perception that the old cultivar T.U. 52-70 was quite variable, since, for example, it was used to develop two other cultivars popular in California, 'T.U. 52-70R' and 'T.U. 52-70 HK' (not included in this study), which can be distinguished phenotypically by growers. In any case, we have to consider that the cause of some of these discrepancies may be the use of dominant markers on heterozygous populations, such as the celery cultivars included in our study. This limitation reduces the efficiency of detection of polymorphism. However, the use of a relatively large number of markers, combined with the pooling of several plants per cultivar, minimizes this potential problem. In summary, all tested celery cultivars could be discriminated from each other based on their AFLP marker profiles, which makes this technique useful for cultivar fingerprinting. Further, this technique could be applied for celery cultivar protection, pedigree analysis and seed purity determination.

\section{Literature Cited}

Guzman, V.L., H.W. Burdine, E.D. Harris Jr., J.R. Orsenigo, R.K. Showalter, P.L. Thayer, J.A. Winchester, E.A. Wolf, R.D. Berger, W.G. Genung, and T.Z. Zitter. 1973. Celery production on organic soils of South Florida. Florida Agr. Expt. Sta. Bul. 757.

Orton, T.J., S.H. Hubert, M.E. Durgan, and C.F. Quiros. 1984. UC1, Fusarium yellows-resistant celery breeding line. HortScience 19:1984

Quiros, C.F., M. McGrath, and J.L. Stites. 1987. Use of stem proteins and isozymes for the identification of celery varieties. Plant Cell Rpts. 6:114117.

Rohlf, F.J. 1993. NTSYS-pc numerical taxonomy and multivariate analysis system, version 2.01. Exeter Software, Setauket, N.Y.

Vilmorin, R.L. 1950. Pascal celery and its origin. J. New York Bot. Garden 51:39-41.

Vos, P., R. Hogers, M. Bleeker, M. Reijans, T.V. Lee, M. Hornes, A. Frijters, J. Pot, J. Peleman, M. Kuiper, and M. Zabeau. 1995. AFLP: A new technique for DNA fingerprinting. Nucleic Acids Res. 23:4407-4414.

Yang, X. and C.F. Quiros. 1993. Identification and classification of celery cultivars with RAPD markers. Theor. Appl. Genet. 86:205-212.

Yang, X. and C.F. Quiros. 1995. Characterizing the celery genome with DNA-based genetic markers. J. Amer. Soc. Hort. Sci. 120:747751 